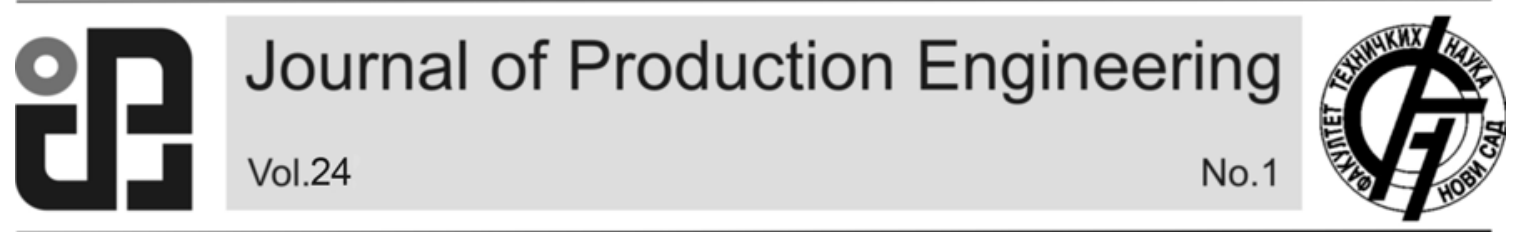

\title{
DETERMINING NOMINAL VALUES OF INPUT PARAMETERS FOR PRODUCTION PROCESS USING DOE
}

\author{
Received: 01 April 2021 / Accepted: 30 May 2021
}

\begin{abstract}
Application of statistical methods in quality improvement of molded parts is presented in this paper. Implementation of two stages of DMAIC improvement cycle in a pre-production process is analysed in detail. DOE method is performed to define nominal values of process parameters of injection molding process. A fractionfactorial design with a single central point is used. A linear mathematical model with included elements of secondorder interaction is defined. Finally, control stage is performed using prior defined nominal values. Process capability test is conducted in order to determine whether the process is capable of producing parts within specified tolerance field.
\end{abstract}

Key words: design of experiments, process capability, injection molding

Utvrđivanje nominalnih vrednosti ulaznih parametara za proizvodni proces korišćenjem DOE. Predstavljena je primena statističkih metoda u poboljšanju kvaliteta livenih delova u ovom radu. Detaljno je analizirana primena dve faze ciklusa poboljšanja DMAIC u pretproizvodnom procesu. DOE metoda se izvodi za definisanje nominalnih vrednosti procesnih parametara procesa injekcionog brizganja. Korišćen je skraćeni faktorski dizajn sa jednom centralnom tačkom. Definisan je linearni matematički model sa uključenim elementima interakcije drugog reda. Konačno, kontrolna faza se izvodi pomoću prethodno definisanih nominalnih vrednosti. Sprovedena je dodatna analiza kako bi se utvrdilo da li je proces sposoban za proizvodnju delova u okviru definisanog polja tolerancije.

Ključne reči: dizajn eksperimenata(DOE), sposobnost procesa, injekciono brizganje.

\section{INTRODUCTION}

Greatest efficiency in improving quality and productivity can be achieved by integrating them in the production process. Implementation of design of experiments (DOE) methodology at the earliest stages of the development cycle, while designing new product or process, improving the design of an existing product, or optimizing production process, is key to success. In order to improve complex multivariable processes, a structured approach could be practical and beneficial. An example of a tool which ensures process improvement and prevents future defects is data-driven quality strategy DMAIC.

Various controlled and uncontrolled factors affect the quality of a molded part. Purpose of DOE is performing minimal number of experimental iterations, while including all influential input factors needed to develop reliable model-based process. A method to determine this value was proposed by MKS [1]. The study presents that fractional factorial model shows approximately same results as full factorial model. However, ten input factors are analysed. This would lead to decreasing experiment efficiency. Also repetition of experiments is not included and therefore experimental error could not be estimated. Crucial part of the planning phase is choice of input factors in DOE. A.O. Andrisano et al [2] propose an algorithm for determining the optimal set of process parameters for given product requirements. S. Rajalingam et al [3] use three input factors with repetition. Abohashima HS et al [4] use four input factors with repetition to determine the influence of chosen parameters on attributive characteristics. Effects are calculated and plotted in Minitab software. S.K. Sharma et al. [5] perform DOE in Autodesk Invertor. Reliability of the experiment depends on CAE and software limitations. Andrisano also includes integration of DOE and CAE method design of simulation experiments (DOSE) method. U.M. Attia et al [6] use different approach in determining the effect of input factors on variable characteristics. Controlled output is weight of molded parts rather than their dimensions. DOE is extremely practical in determining optimal input parameters in a production process, which result in higher productivity and quality. U. D. Gulhane et al. [7] investigate the effect of machining parameters on surface finish of a machined part and define their optimal values. D. Bajić et al. [8] optimises a milling process using DOE. T. Tamizharasan et al. [9] use DOE as an approach in defining the geometry of cutting tool. Pantelis N. Botsaris et al. [10] use sensor-based approach in order to monitor wearing of cutting tool in real time and detect its breakage in drilling processes. Using DOE models, machining parameters are varied. Optimal values of parameters and work conditions, which lead to longer tool life, are defined. However, DOE method is not limited on production of mechanical parts and has a broader significance. For example, Verma et al. [11] present the effects of key process variables for a microfluidization unit using fractional model. C. Yuangyai et al. [12] emphasise the impact DOE has on the advancement of nanotechnology and nanomanufacturing. 
Review of relevant literature shows that while the improvement stage is analyzed in detail, the control stage is not included. Therefore, capability of the improved process could not be determined. Proposed paper complements process improvement and control by integrating both stages. A case study is analyzed. The purpose is to examine the correlation between the input process parameters of an injection process and critical for assembly (CTA) dimension of a molded part. While variable characteristics are the controlled output, attributive characteristics must not be impaired. Analyze of mold construction is not included, but only process parameters are varied. Two stages of DMAIC are used in determining nominal values of process parameters and controlling output of previously defined injection molding process parameters. The experiment is performed during a trial production. The prime purpose is molding parts with variable characteristics closest to nominal, in the specified tolerance field, while achieving satisfying attributive characteristics. Furthermore, a trial production using the adjusted nominal values is performed, in order to provide sufficient data for process capability analysis. Statistical analysis of the results is applied to provide a better interpretation of the experiment. Based on the empirical results, an adequate and valid linear mathematical model has been generated, using Microsoft Excel.

\section{METHODOLOGY}

The experimental part of this study case was performed in two phases, shown in figure 1. In the first phase, influence of six factors at two levels was examined using a full factorial model of DOE. Selection of input parameters was done based on research [13] and empirical experience, considering chemical composition of the granule, part's geometry and weight and nature of the controlled CTA dimension. Consequently, the most influential factors are used as an input in the second phase of DOE. Experiment based on fractional factorial model with one central point [14] is performed, in order to examine the influence of four most influential factors and their interactions.

Based on acquired data, a mathematical regression model is defined. Mathematical regression models could easily be solved and used in production for process understanding, design and control. This approach could lead to efficient development and implementation of a robust process that ensures consistent production with desired quality level. The model is defined using Microsoft Excel. Consequently, an Excel template is created for conducting a simple and fast analysis of the generated data from DOE. This template is especially useful for non-experienced researchers. All the user would have to do is input the collected data and a mathematical model would be generated. While performing DOE calculations, all the steps of the mathematics of this method are shown and could easily be studied. The user could understand the meaning of the coefficient values and conducted model analyses. A standard statistical software performs black-box calculations and only generates required output data. Also, if a potential engineering change in part or process is made, models would have to be updated. Created Excel template could be used to monitor model performance over the life cycle of the production process. An approach for monitoring model performance is proposed in this study. It includes periodic comparison of model prediction to a reference method. Consequently, two hypotheses are set:

H1: Obtained results from performed experiment match predicted results from generated mathematical model which leads to defining identical nominal values of machine process parameters.

H2: Obtained results from performed experiment do not match predicted results from the mathematical model, i.e. analytical calculations do not match the real process.

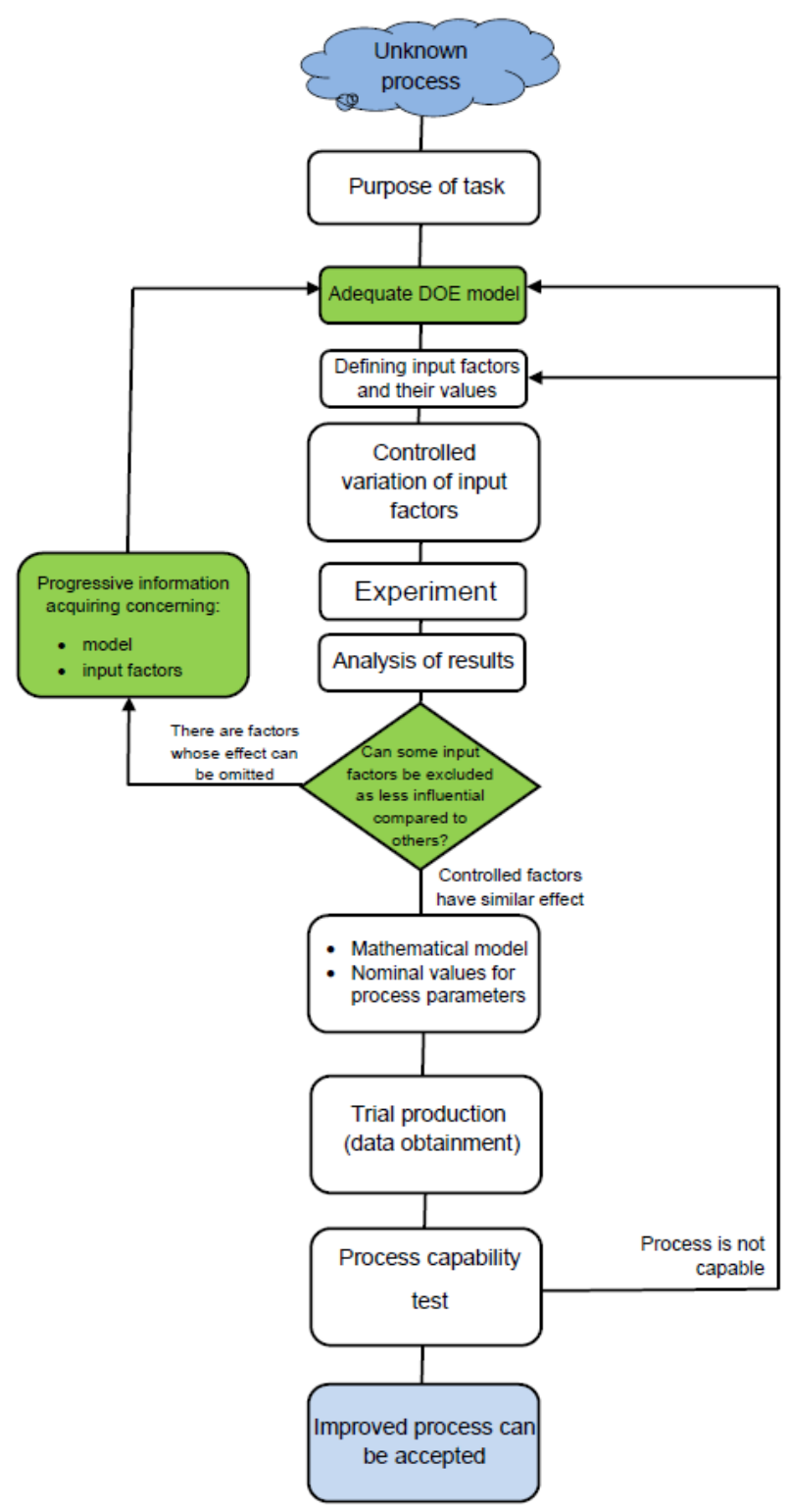

Fig. 1. Algorithm of activities

\section{CASE STUDY}

\subsection{Design of experiments (DOE)}

Prior to experiment realization, all stages of its preparation have to be completed. First of all, machine, operator, material and work conditions have to be 
defined. The experiment is performed on a single machine during one working week, by the same operators. This minimizes the possibility of variations caused by machine or operator. The used granule is defined in the specification of the part - ABS + PC, which has to be dried for 3 hours at $120^{\circ} \mathrm{C}$.

Controlled dimension (CTA) is defined in the technical drawing of the part, and its value is $209 \pm 0.46 \mathrm{~mm}$, shown in figure 2 .

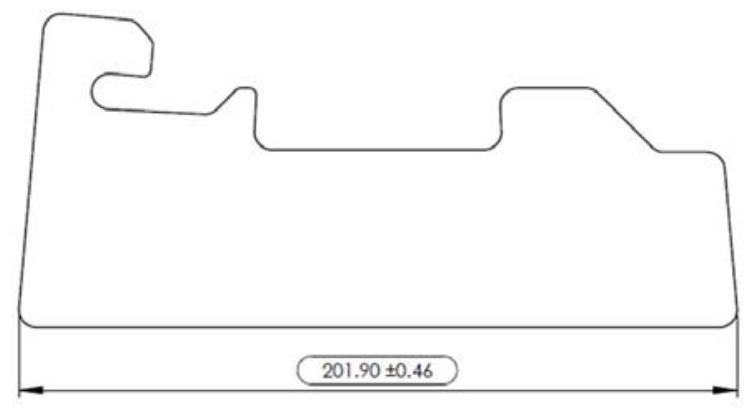

Fig. 2. Controlled dimension of the moulded part

Also, the basic principles of DOE have to be fulfilled [13]:

- Randomization refers to random controlled samples and order of individual tests. This is necessary because statistical methods require independently distributed errors and random variables. Proper randomization of the experiment allows external factors (which may be present) to be brought to an average value. In some situations, randomization is difficult to be performed, for example: mold temperature is one of the factors examined and has levels of 50 and $90{ }^{\circ} \mathrm{C}$. Randomization is impractical if the first test is performed at mold temperature of $50{ }^{\circ} \mathrm{C}$, then the next one at $90^{\circ} \mathrm{C}$, and then again at $50{ }^{\circ} \mathrm{C}$. In other words, mold should be heated to $90^{\circ} \mathrm{C}$, then cooled to $50{ }^{\circ} \mathrm{C}$, then reheated to $90{ }^{\circ} \mathrm{C}$, etc. which results in longer downtimes and reduced efficiency.

- Replication of experiment is independently conducted test for each combination of factors. It provides enough information for calculation of experimental error, which presents the basic unit of measurement for determining whether the observed differences in data are statistically different. Additionally, it provides greater accuracy in estimating the mean response value for a single level of factors in the experiment. In order to effectively perform this principle, it is necessary to include only most influential factors or use a fractional-factorial model.

- Blocking of samples or dividing samples into blocks under homogenous working conditions is a technique used to eliminate or reduce impact of uncontrollable input factors and improve calculated effect accuracy. This is useful, because often it is impossible to perform all repetitions within DOE under constant or homogeneous conditions.

Based on research and experience, six most influential machine process parameters and their process windows are chosen. Factors such as die opening speed and ejection speed do not directly affect the process and therefore are omitted. Object of analysis is the influence of the following parameters [15]:

- Mold temperature (A) is responsible for maintaining the flow of molten plastic and complete filling of the cavity. The temperature of the molten plastic at the end of the filling phase should be within the recommended range for the specified granule. This applies to amorphous and crystalline materials. Low level should be the minimum value at which flow of molten granulate is enabled. High level is selected as the maximum at which there is no granule degradation. Selected levels of this factor are 50 and $90^{\circ} \mathrm{C}$.

- Injection speed (B): Low level is selected as the minimum velocity at which the cavities are fully filled and high level is the maximum velocity at which no flash is formed. Selected levels are 25 and $100 \mathrm{~cm}^{3} / \mathrm{s}$.

- Holding pressure (C) is one of the most important factors and must always be considered as a factor for DOE. Low level is selected as the minimum velocity at which the cavities are fully filled and high level is the maximum velocity at which no flash is formed. Selected levels of this factor are 400 and 800 bar.

- Cooling time (D): Low level is selected as the minimum value at which solidification at the gates is achieved. High level is taken as the lower value multiplied by three. Levels are 5.5 and $15 \mathrm{~s}$.

- Screw rotation (E): Low level should be the minimum value which allows proper melting of the granule and results in forming a homogenous molten plastic. High level is selected as the maximum at which there is no granule degradation. Selected levels of this factor are 90 and $120 \mathrm{upm}$.

- Temperature of molten plastic $(F)$ : In the case of amorphous materials, the recommended melting temperature range is wide and thus it may affect the shrinkage and dimensions of the part. ABS $+\mathrm{PC}$ is amorphous material, and therefore this factor is analyzed. Levels are selected based on material specification: 250 and $280^{\circ} \mathrm{C}$.

\begin{tabular}{|c|c|c|c|}
\hline Parameter & Unit & \multicolumn{2}{|c|}{ Levels } \\
\hline A: Mold temperature & ${ }^{\circ} \mathrm{C}$ & 50 & 90 \\
\hline B: Injection speed & $\mathrm{cm}^{3} / \mathrm{s}$ & 25 & 100 \\
\hline C: Pressure & bar & 400 & 800 \\
\hline D: Cooling time & $\mathrm{S}$ & 5.5 & 15 \\
\hline E: Temperature of & ${ }^{\circ} \mathrm{C}$ & 250 & 280 \\
\hline molten plastic & & & \\
\hline F: Screw speed & upm & 90 & 120 \\
\hline
\end{tabular}

Table 1. High and low levels of input parameters 


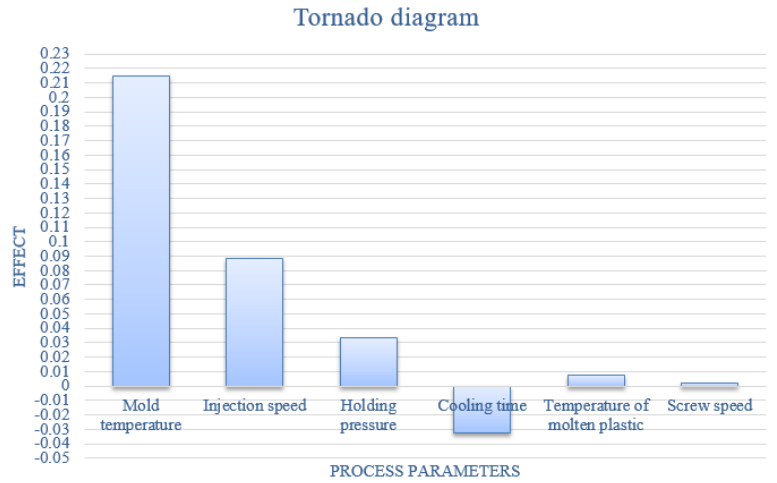

Fig. 3. Tornado diagram

There are up to four process parameters that will cause a significant variation in part dimensions [14]. In order to perform a practical and efficient DOE with replications, it is necessary to select the most influential factors.

Main effect value of the input factors can be calculated using the following relation:

$$
A=\overline{y A_{+}}+\overline{y A_{-}}=\frac{1}{n}\left(\sum_{i=1}^{n} y A_{i+}-\sum_{j=1}^{n} y A_{j-}\right)
$$

\begin{tabular}{|c|c|c|c|c|c|c|c|c|c|}
\hline & $\mathbf{1}$ & $\mathbf{2}$ & $\mathbf{3}$ & $\mathbf{4}$ & $\mathbf{5}$ & $\mathbf{6}$ & $\mathbf{7}$ & $\mathbf{8}$ & $\mathbf{9}$ \\
\hline $\mathbf{A}$ & + & + & + & + & - & - & - & - & $\mathbf{0}$ \\
\hline $\mathbf{B}$ & + & + & - & - & + & + & - & - & $\mathbf{0}$ \\
\hline $\mathbf{C}$ & + & - & + & - & + & - & + & - & $\mathbf{0}$ \\
\hline $\mathbf{D}$ & + & - & - & + & - & + & + & - & $\mathbf{0}$ \\
\hline
\end{tabular}

Table 2. Experimental matrix for fractional factorial model $2^{4-1}$ with one central point

A full factorial $2^{6}$ model of DOE was performed and gained data is analyzed using a statistical tool - Tornado diagram, figure 3 . A total of $2^{6}=64\left(2^{\mathrm{k}}, 2\right.$ - number of levels for each factor, k-number of factors varied) combinations of the experiment were performed, without repetition. The diagram shows that factors with lowest influence are temperature of molten plastic(E) and screw speed(F).

The second phase was performed by varying A-D factors, using a fractional factorial model $2^{4-1}$ with one central point. In order to estimate the experimental error, for each combination of values the experiment was repeated 10 times. A total of $\left(2^{4-1}+1\right) \cdot 10=90$ parts have been molded.

Next, transforming the gained data into useful information is in order. According to previous research in the field of injection molding [14], recommended model for describing this process is linear mathematical model which involves first-order interaction members. Specific form of regression model for $2^{4} \mathrm{DOE}$ is:

$$
\begin{aligned}
& y=\beta_{0}+\beta_{1} x_{1}+\beta_{2} x_{2}+\beta_{3} x_{3}+\beta_{4} x_{4}+\beta_{12} x_{1} x_{2}+ \\
& +\beta_{13} x_{1} x_{3}+\beta_{14} x_{1} x_{4}+\beta_{23} x_{2} x_{3}+\beta_{24} x_{2} x_{4}+\beta_{34} x_{3} x_{4} \\
& +\varepsilon
\end{aligned}
$$

Mathematical model is a quantitative correlation (equation) between response and significant input factors. A lower order polynomial model is usually considered appropriate [14]. Based on the presented Pareto diagram of effects in figure 4, the preliminary model is chosen:

$$
\begin{aligned}
& y=\beta_{0}+\beta_{1} x_{1}+\beta_{2} x_{2}+\beta_{3} x_{3}+\beta_{4} x_{4}+\beta_{12} x_{1} x_{2}+ \\
& +\beta_{14} x_{1} x_{4}+\varepsilon
\end{aligned}
$$

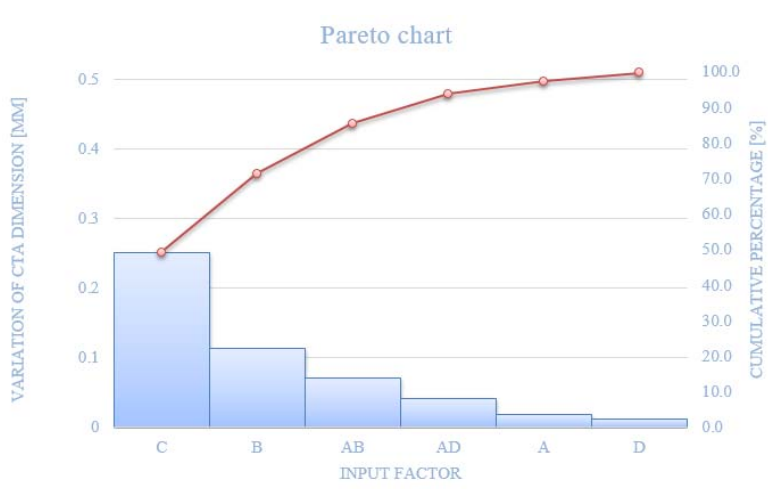

Fig. 4. Pareto chart

Calculated coefficient values:

$$
\begin{gathered}
\beta_{0}=201.765 \\
\beta_{1}=-0.009 \\
\beta_{2}=0.0565 \\
\beta_{3}=0.1255 \\
\beta_{4}=0.006 \\
\beta_{12}=-0.036 \\
\beta_{14}=0.021
\end{gathered}
$$

Consequently, the regression model is:

$$
\begin{aligned}
& y=201.765-0.009 x_{1}+0.0565 x_{2}+0.1255 x_{3}+ \\
& +0.006 x_{4}-0.036 x_{1} x_{2}+0.021 x_{1} x_{4}
\end{aligned}
$$

After conducting Student's analysis, coefficients $\beta_{1}$ and $\beta_{4}$ proved to be negligibly small and insignificant compared to the others, and therefore can be omitted:

$$
\begin{aligned}
& y=201.765+0.0565 x_{2}+0.1255 x_{3}-0.036 x_{1} x_{2}+ \\
& +0.021 x_{1} x_{4}
\end{aligned}
$$

The experiment satisfies all necessary assumptions for carrying out an ANOVA analysis:

- all measured values have to be normally distributed (concluded from plotted histogram in figure 5),

- equal variances (or standard deviation values) among groups (concluded from Cochran's test for group variance),

-random sampling. 


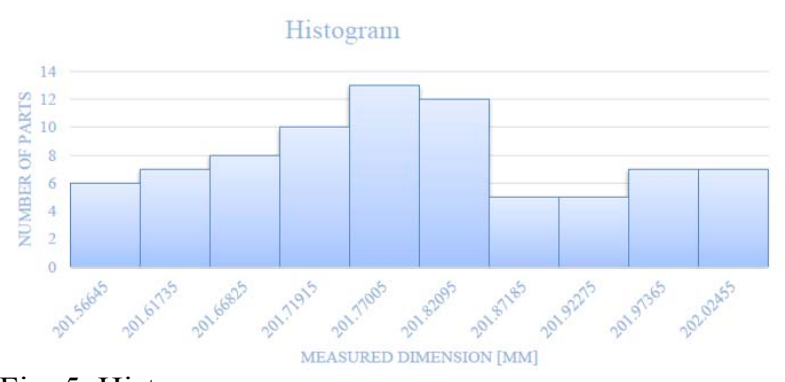

Fig. 5. Histogram

ANOVA analysis decomposes total variance into variability occurred under the influence of controlled factors and uncontrolled (residual) factors. After conducting ANOVA analysis, it can be concluded that mean values from at least two individual groups differ significantly. In other terms, change of CTA value is caused by variation of the controlled input factors and the proposed model is significant.

Additional analysis of adequacy of the regression model is an integral part of DOE. Whether the model is an accurate representation of the collected data can be deduced by conducting the Fisher lack-of-fit test. This test proves that there are no factors that significantly affect the controlled response, which have not been included in the model.

That one may perform a simple and fast analysis of the generated data from DOE, an Excel template has been developed. All the user would have to do is input the collected data and a mathematical model would be generated. Furthermore, previously performed analyzes that prove significance of the data and adequacy of the mathematical model to characterize the system are included in it.

By inputting values of process parameters (that belong in the studied process window) in the mathematical model, which is significant and adequate, the value of the CTA dimension can be calculated. According to the results (shown in table 3), it can be concluded that nominal values of the process parameters are the high levels of all four input factors:

\begin{tabular}{|c|c|}
\hline Process parameters & Nominal values \\
\hline Mold temperature & $90^{\circ} \mathrm{C}$ \\
\hline Injection speed & $100 \mathrm{~cm}^{3} / \mathrm{s}$ \\
\hline Holding pressure & $800 \mathrm{bar}$ \\
\hline Cooling time & $15 \mathrm{~s}$ \\
\hline
\end{tabular}

Table 3. Nominal values of process parameters

$$
\begin{gathered}
y=201.765+0.0565 \cdot(+1)+0.1255 \cdot(+1)- \\
-0.036 \cdot(+1) \cdot(+1)+0.021 \cdot(+1) \cdot(+1) \\
y=201.9315 \mathrm{~mm}
\end{gathered}
$$

Results obtained from the performed experiment and the calculated values from the mathematical model are corresponding. In other words, identical nominal values of the process parameters of the machine are defined analytically and experimentally.

\subsection{Process capability test}

Prior to releasing a process in serial production with defined nominal values from DOE, control stage is in order. Trial production was performed in duration of five work days in three shifts. Five parts (their CTA dimension) were controlled on every four work hours.

This test shows whether the process is capable to produce parts in the specified tolerance field [12]. Capability test is conducted by calculating the process capability and index of process capability parameters:

$C_{P}=\frac{U S L-L S L}{6 \sigma}$

$C_{P k}=\frac{U S L-\bar{x}}{3 \sigma}=\frac{\bar{x}-L S L}{3 \sigma}$

USL - upper specification limit

LSL - lower specification limit 6- standard deviation

$$
V=\frac{1}{n-1} \sum_{i=1}^{n}\left(x_{i}-\bar{x}\right)^{2}
$$

$\overline{\mathrm{X}}$-mean value of $\mathrm{n}$ samples

$$
\bar{x}=\frac{1}{n} \sum_{i=1}^{n} x_{i}
$$

Standard deviation:

$$
\sigma=\sqrt{V}
$$

Values of capability parameters, table 4 , show that the process is capable to produce parts within the specified tolerance field.

\begin{tabular}{|c|c|}
\hline Standard deviation & $\mathbf{0 . 0 4 5}$ \\
\hline USL & 202.36 \\
\hline LSL & 201.44 \\
\hline Cp & 3.4 \\
\hline Cpk & 3.7 \\
\hline
\end{tabular}

Table 4 . Values of process capability test parameters

\section{CONCLUSION}

DOE methodology was used in order to determine nominal values of process parameters of an injection molding process. After stages of planning, design and performance of DOE, from which relevant data were collected and analyzed by statistical methods, a conclusion has been reached. Defined nominal values of input process machine parameters from DOE coincide with the conclusion drawn from the mathematical model obtained in the case study. Hypothesis H1 is accepted. Fractional factorial model with one central point has been used, in order to meet the basic principles of 
experimental design, with a minimum number of iterations. A linear model with second-order interaction members has been used as the most appropriate model for defining an injection process. Only most influential interaction factors were included.

Furthermore, a trial production process was performed and process capability test was perfomed. Results show that the process with prior defined nominal values of process parameters, is capable to produce parts within the specified tolerance field.

\section{REFERENCES}

[1] MKS Instruments Inc., "The Optimization of Injection Molding Processes Using Design of Experiments" [Online].Available: https://www.mksinst.com/mam/celum/celum_assets/ resources/SenselinkQMDOE-ppNote.pdf [Accessed: 2012].

[2] Andrisano A. O., Gherardini F., Leali F., Pellicciari M., Vergnano A. : Design Of Simulation Experiments method for Injection Molding process optimization, International conference Innov. Meth. Prod. Des., Venice, Italy, 2011, pp. 476-486, 2011

[3] Rajalingam S., Bono A. and Sulaiman J: Determining Optimal Moulding Process Parameters by Two Level Factorial Design with Center Points, J. B. Sri Lankan Journal of Applied Statistics, vol. 11, issue 1, pp. 63-88, 2012, doi: 10.4038/sljastats.v12i0.4968

[4] Abohashima H.S., Aly M.F., Mohib A., Attia H.A.: Minimization of Defects Percentage in Injection Molding Process using Design of Experiment and Taguchi Approach, Journal of Industrial Engineering and Management, vol. 4, issue 5, pp.1-6, 2015, doi: 10.4172/2169-0316.1000179

[5] Sharma K.S., Sharma V., Dadhich M., Jain S.K., Agarwal D.: Optimization of process parameters of PIM process using DOE technique Taguchi, International Journal on Theoretical and Applied Research in Mechanical Engineering, vol. 4, issue 3, pp. 34-38, 2015.

[6] Attia U.M., Alcock J.R.: Optimising process conditions for multiple quality criteria in microinjection moulding, The International Journal of Advanced Manufacturing Technology, vol.50, issue 5-8, pp. 533-542, 2010, doi: 10.1007/s00170-010$\underline{2547-0}$

[7] Gulhane U. D., Ayare S. P., Chandorkar V.S., Jadhav M. M. : Investigation of turning process to improve productivity for better surface finish of AL7075-t6 using DOE, International Journal of Design and Manufacturing Technology, vol. 4, issue 1, 2013.

[8] Bajić D., Jozić S., Podrug S. : Design of experiment's application in the optimization of milling process, METABK, vol. 49, issue 2, pp. 123126,2010

[9] Tamizharasan T., Barnabas J.K. : Optimisation of cutting tool geometry based on flank wear-DOE, PSO and SAA approach, Indian Journal of Engineering and Material Science, vol. 21, issue 5, pp. 543-556, 2014.
[10] Botsaris P. N., Tsanakas J. A., Vogiatzi M. E.: Tool Wear Monitoring by Design of Experiments (DOE) for Drilling, 24th International Comadem Conference, Stavanger, Norway, pp.1-13, 2011.

[11] Verma S., Lan Y., Gokhale R., Burgess D.J.: Quality by design approach to understand the process of nanosuspension preparation, International Journal of Pharmaceutics vol. 377, issue 1-2, pp. 185-198, 2009, doi: 10.1016/j.ijpharm.2009.05.006

[12] Yuangyai C., Nembhard H.B.: Design of Experiments: A Key to Innovation in Nanotechnology in Emerging Nanotechnologies for Manufacturing, W. Ahmed and M. J. Jackson, Oxford, UK, Elsevier, 2009.

[13] Kulkarni S.: Robust process development and scientific molding-2nd edition, Theory and Practice, Cincinnati, Kanser Publications, pp: 207-234, 2017, doi: $10.3139 / 9781569905876$

[14] Montgomery D. C.: Design and Analysis of Experiment- 8th Edition, New York, John Wiley \& Sons Inc., 2013.

[15] Mitra A.: Fundamentals of Quality Control and Improvement - 3rd Edition, New York, John Wiley \& Sons Inc., Chapter 3: "Statistical Process Control”, pp.263-288, 2008, doi: $10.1002 / 9781118491645$

\section{Acknowledgements}

The authors would like to acknowledge Professor Mikolaj Kuzinovski, Ph.D (in memoriam) whose research in the field of DOE had a huge impact on the development of DOE methodology at the institute of Production Engineering and Management, Faculty of Mechanical Engineering, Ss. Cyril and Methodius University, Skopje, North Macedonia.

\section{Funding}

The experimental part of the research was organised and sponsored by the delegation of the German Economy in Northern Macedonia, Süddeutsche Kunststoff-Zentrum (SKZ) from Würzburg and the company Kostal.

Authors: Anastasija Ignjatovska grad. mech. eng., Professor Mite Tomov Ph.D, ., "Ss. Cyril and Methodius" University in Skopje, Faculty of Mechanical Engineering-Skopje, Karpos, 1000 Skopje, North Macedonia,

E-mail: aneignjatovska@yahoo.com mite.tomov@mf.edu.mk 